\title{
ESTUDIOS
}

\section{Sobre "Conjunciones y Disyunciones"}

Un estudio comparativo del panorama de las literaturas de lengua castellana y francesa de los últimos veinte años subrayaría probablemente un hecho que, pese a su carácter anodino y a primera vista obvio, merece con todo alguna reflexión: mientras la escasísima obra crítica escrita en nuestro idioma contrasta por su rareza con una granada producción poética y un extraordinario florecimiento de la narrativa--hasta el punto de devolver a la lengua española en lo que se refiere a la novela, una primacía que parecía perdida para siempre desde la muerte de Cervantes--el panorama literario francés nos ofrece una imagen simétricamente opuesta; en él, el espléndido desarrollo del ensayo y la crítica sobresale entre la medianía satisfecha de la poesía y el largo periodo de autocrítica y tanteo de una novela cuyo proclamado afán renovador no ha dado aún los resultados que razonablemente hubiéramos podido esperar. Si por un lado hallaríamos en Francia muy pocos nombres que oponer a la lista de los Borges y Paz, Carpentier y Lezama, García Márquez y Fuentes, Vargas Llosa y Cabrera Infante, por otro, nos veríamos igualmente en un aprieto si pretendiéramos buscar en el mundo de habla hispana los equivalentes de un Benveniste, un Blanchot, un Lèvi-Strauss o un Barthes (e incluso a Todorov, Genette, Sollers, o Kristeva): a la penuria multisecular del pensamiento crítico de que adolece nuestra lengua (penuria cuyas raices se remontan a la quiebra de la convivencia intercastiza medieval y la persecución intelectual "anti-judaica") corresponde un auge espectacular de la creación poética y narrativa; a la singular "creatividad" del ensayo y la crítica en Francia, una anemia e inseguridad muy marcadas en el campo tradicional de la poesía y la novela. Digo "tradicional" pues, como vamos a ver, dicho esquema abarca sólo un aspecto de la cuestión y las cosas son en realidad bastante más complejas tanto cuanto que uno de los rasgos esenciales de la literatura de nuestro tiempo radica precisamente en la supresión de las aduanas y fronteras establecidas entre los géneros clásicos en favor de una producción textual descondicionada que los englobe y a su vez los anule: textos que sean a un tiempo crítica y creación, literatura y discurso sobre la literatura y, por consiguiente, capaces de contener en sí mismos la posibilidad de una lectura simultáneamente poética, crítica, narrativa. Bajo este concepto podríamos estimar (es una mera hipótesis) la insólita y admirable explosión de la narrativa en lengua española de los últimos años (especialmente 
en Latinoamérica) como el canto de cisne de un género condenado a morir en su forma actual--deslumbrador castillo de fuegos de artificio destinado a ocultarnos quizá la escueta realidad de su eclipse ante una nueva visión del hecho literario concebido como libérrima opción de lecturas, a distintos niveles, en el interior del espacio textual. La prodigiosa riqueza actual de nuestra narrativa sería menos, en este caso, una apuesta lanzada a lo por venir que un signo formal del pasado: una inquieta, apresurada, febril recuperación del tiempo perdido tras el desarraigo brutal de la dimensión imaginativa del campo de la novela con posterioridad al Quijote--exactamente a la inversa de lo que ocurre en Francia, en donde el agotamiento paulatino de los géneros "creativos" tradicionales se conjuga con un desenvolvimiento inverso del pensamiento crítico, centrado en el propósito de sentar las bases de una producción textual aun en agraz, pero enteramente liberada ya de la censura monosémica inherente a la existencia de géneros minuciosamente codificados. El diferente estadio de desarrollo o, por mejor decir, decrepitud de las formas literarias canonizadas se relacionaría así con la evolución desigual del corpus crítico respecto a ellos--lo que indicaría tal vez (lo repito, es una simple hipótesis) que la buena salud aparente de que hoy disfruta nuestra novela es una manifestación puramente transitoria y efímera, como algunos síntomas lo muestran ya. Hoy más que nunca la introducción de un instrumental crítico en el ámbito de nuestra lengua es una necesidad insoslayable si los países de habla española pretenden desempeñar algún papel en la asimilación y ordenación creadoras de una fase histórica que, como la actual, recuerda en tantos aspectos la que vivieron los hombres del Renacimiento--cuando España encarnó pasajeramente la aspiración a un saber sin fronteras antes de enclaustrarse para siempre en el panteón de la autosuficiencia, el pensamiento monolítico, la cerrazón ortodoxa.

Estas reflexiones--en cuya adecuada formulación no puedo detenerme ahora--nos ayudan a situar en cualquier caso el transfondo cultural en el que se inscribe la obra ensayística de Octavio Paz, obra tan densa, variada y rica como excepcional en un mundo en el que, como señalara en una ocasión Cernuda, no existe "espíritu crítico ni crítica, y donde, por lo tanto, la reputación de un escritor no descansa sobre una valoración objetiva de su obra.' Pues Paz--no está de más recordarlo en un ambiente influido aún por la segmentación de los géneros literarios--no es sólo uno de los grandes poetas actuales de la lengua: es asimismo uno de los rarísimos pensadores que, expresándose en ella, han alcanzado una difusión que rebasa ampliamente el marco de sus fronteras. Desde la publicación, hace ya más de treinta años, de su admirable Laberinto de la soledad hasta su esclarecedor estudio sobre Lèvi-Strauss, pasando por El arco y la lira y Corriente alterna, la meditación creadora de $\mathrm{Paz}$ no ha cesado de extenderse sobre campos tan dispares como el arte y la política, la antropología y el sicoanálisis, la poesía y la ciencia sin abandonarse por ello a esa facilidad divulgadora que tan a menudo rebaja la obra de Ortega, devolviendo a la lengua española su capacidad, perdida por siglos, de convertirse en instrumento y vehículo de un pensamiento no sometido a ningún sistema de dogmas--de un pensamiento capaz de abrazar, sin anularse por ello, las distintas corrientes ideológicas surgidas de la Ilustración y la Revolución Industrial, de Rousseau y Sade, Hegel y Marx, Saussure y el surrealismo, y de explorar la complejísima y contradictoria faz del mundo de hoy sin recurrir a ninguno de los esquemas que habitualmente la encubren. ${ }^{1}$ Actitud inusitada que nos remite, por otra

\footnotetext{
${ }^{1}$ Compárase, por ejemplo, la grave y precisa reflexión de Paz sobre la praxis revolucionaria con la aceptación sumisa y acrítica de otros grandes poetas comoNeruda o Alberti de todas-o casi todas-las aberraciones realizadas en nombre de la Iglesia Revolucionaria Institucionalizada.
} 
parte, a la realidad a que anteriormente nos referíamos: la imposibilidad de separar en lo futuro en compartimentos estancos la obra poética y la obra crítica en la medida en que ambas constituyen diferentes aspectos de un mismo proceso y la creciente autoreflexión de la poesía es un hecho simétrico a la gradual "poetización” de la crítica. Poeta-crítico o crítico-poeta, Octavio Paz nos brinda el mejor ejemplo de una obra que desborda y cubre las formas literarias canonizadas y postula una incitante concepción del texto como dinámica pluralidad de lecturas. Un libro como Conjunciones y disyunciones ilustra muy bien, a mi modo de ver, esta múltiple opción del lector enfrentado no sólo a un verdadero, casi tántrico festín de ideas (ah, qué contraste cruel con el adusto y escuálido cubierto del común de los pensadores hispanos!) sino también (y éste es un aspecto fundamental de la concepción del autor) de palabras: divagación poética y, al mismo tiempo, aproximación crítica a una serie de hechos esenciales de nuestro pasado, presente y sin duda, futuro; digresión sobre la picardía mexicana pero, también, cala profundísima en el ser de una vertiginosa variedad de culturas (desde México a China, desde la India a España).

Uno de los rasgos peculiares del ensimismamiento hispano ha sido siempre su falta de interés por las formas de vida y civilización ajenas, ausencia de curiosidad que, añadida a la ya mencionada carencia de espíritu crítico, aclara en gran medida nuestra escasísima contribución al estudio de otras culturas (incluso de aquellas histórica y físicamente próximas) de la que con tanta razón se lamentaba Américo Castro. ${ }^{2}$ En Conjunciones $y$ disyunciones, Paz se sitúa en las antípodas de la tradición peninsular provinciana y se sirve de su museo imaginario personal para trazar, partiendo del binomio cuerpo/no cuerpo, una extraordinaria red de paralelismos y oposiciones que va del budismo tántrico, el hinduismo y Confucio al barroco crepuscular español y la moral crematística puritana. Su inagotable curiosidad intelectual y cultura vastísima sirven de trampolín para una serie de reflexiones audaces sobre economía y amor, excremento y lenguaje que lo confirman por uno de los espíritus más lúcidos de la época.

Tomando como punto de arranque los análisis de Max Weber, Erich Fromm y Norman O. Brown, Paz se esfuerza en desenredar y ordenar la telaraña de afinidades y divergencias existentes entre las distintas culturas del mundo indoeuropeo y extiende incluso el campo de investigación a las civilizaciones china y precolombina con el propósito confesado de establecer un juego de simetrías parecido a aquel en que soñara Valèry cuando evocaba la posibilidad de diseñar un esquema de los cambios literarios a fin de mostrar que el cuadro general de los desvios a la norma obedece a un ars combinatoria rigurosa o, si se quiere, a "una distribución simétrica de medios de ser original". La oscilación de los signos "cuerpo" y "no cuerpo" a lo largo de la historia de las civilizaciones sería así el eje en torno al cual giran las concepciones religiosas y sociales, con sus magnos, ponderosos edificios ideológicos, dogmáticos y rituales--hipótesis sumamente fecunda que, como el juego de dicotomías primarias de Lévi-Strauss, nos permite tejer una serie de relaciones complejas (hechas de semejanzas y oposiciones) fundadas precisamente en el diálogo ininterrumpido de los dos signos que el autor cruza y descruza en el espacio rectangular de la página:

${ }^{2}$ La impermeabiliclad del 98 al descubrimiento dei musée ims rinaire que realizara Picasso a principios de siglo es un buen ejemplo de lo que digo. 
frente al vocabulario neutro y abstracto de la moral [se refiere al protestantismo], las palabras genitales y las cópulas fonéticas y semánticas [del tantrismo]; frente a las plegarias, los sermones y la economía del lenguaje racional, las mantras y sus cascabeles. Un lenguaje que distingue entre el acto y la palabra y, dentro de ésta, entre el significante y el significado; otro que borra la distinción entre la palabra y el acto, reduce el signo a mero significante, cambia el significado, concibe el lenguaje como un juego idéntico al del universo en el que el lado derecho y el izquierdo, lo masculino y lo femenino, la plenitud y la vacuidad son uno y lo mismo.

Las limitaciones del presente artículo nos impiden analizar, como sería nuestro deseo, todo un haz de simetrias convergentes y opuestas respecto al alimento y la muerte, la retención anal y el lenguaje que traducen la oscilación histórico-espacial de los dos signos básicos, y nos limitaremos a tocar ahora un aspecto parcial del binomio que interesa particularmente a los españoles: me refiero al brillantísimo paralelo que dibuja Paz entre al catolicismo hispano y la moral protestante inglesa a través de los ejemplos de Quevedo y Swift y su estudio magistral de la injustamente preterida, y mal interpretada, escatología del primero.

En un seminario sobre el tema "Erotismo y represión en la literatura española. Siglos XIV-XVI', destinado a los alumnos graduados de New York University, procuré analizar lo mejor que pude y supe, en el contexto de la lucha intercastiza, la reducción y transmutación progresiva del signo "cuerpo" a lo largo de este período, desde su expresión llana y libre en el admirable repertorio amoroso del Arcipreste hasta las fúnebres, "luminosas exequias del sol-excremento" del gran poeta escatólogo. En efecto: paralelamente a la persecución y ahogo de la inquietud intelectual "judaica", una lectura aún somera de nuestra literatura revela, a partir del siglo XV, una represión sistemática de la tradición de sensualidad hispano-árabe. Coincidiendo con el eclipse militar de los musulmanes, el sabroso erotismo de los textos medievales deserta paulatinamente de la escena literaria española, no sin adoptar antes la forma exasperada y convulsa que tanto sorprende y choca, hoy todavía, a numerosos " especialistas" en el Siglo de Oro. " A partir de entonces asistimos a una institucionalización de la represión del signo "cuerpo" que, conjugada con la del intelecto, ha pasado a ser uno de los ingredientes esenciales de la moderna personalidad hispana. Hasta la fecha, casi ningún historiador o ensayista ha calibrado como se debe la importancia de este fenómeno y su formidable impacto en la configuración mental y vital del país. Como observa con acierto Xavier Domingo en uno de los pocos ensayos consagrados al tema,

el árabe ha integrado el acto sexual en la estructura de sus aspiraciones más elementales. El cristiano, al contrario, tiende a excluir el sexo, a negarlo. El sentimiento y la sexualidad son para el árabe cosas indisolubles. Para el cristiano todo lo que concierne al sexo es nefasto y puede contaminar el alma. Aunque cristianos y musulmanes vivían en el mismo suelo, de manera casi idéntica, sus

3 Los comentarios de Menéndez Pidal a algunos poemas satíricos de Góngora merecen figurar en cualquier antologia futura de la Mojigateria Universal. 
concepciones en materia tan esencial como el amor se oponian de modo tan rotundo que no es extraño que su guerra, dure ocho siglos y termine con la aniquilación del vencido. Todo lo que el español lleva en sí de árabe es reprimido sin piedad, y en primer término, la sexualidad.

El signo "cuerpo" se manifiesta sin tapujos en tiempos del poeta mudéiar Juan Ruiz, "cuando Castilla, escribe Américo Castro, comenzaba a organizar sus placeres y no se avergonzaba de ello'. El Libro del buen amor es, a fin de cuentas, un repertorio de los goces de la época y su autor no incurre en la sublimación petrarquista ni el regodeo escatológico a los que se entregarán luego, por turno, algunos de nuestros mejores escritores. Por eso mismo el papel que desempeña en la literatura española es fundamental, y puede compararse tan sólo con el de las otras dos obras maestras de aquella, la Celestina y el Quijote. Juan Ruiz representa el único momento de nuestra historia en que el binomio cuerpo/no cuerpo mantiene un equilibrio armonioso, recordándonos así, como le recuerda a Paz, que "no somos únicamente descendientes de Quevedo" y gracias a él me reconcilio también--a lo menos en el lapso de su lectura--con la gente de habla española. Todo eso, claro está, fue consecuencia directa de la profunda familiaridad del Arcipreste con el mundo árabe, familiaridad que le permitía una pacífica convivencia entre el "erotismo y la religión, imposible como simultaneidad para el cristiano, cuya creencia--como nos recuerda Castro--no le permite abandonarse justificadamente a las dulzuras del amor carnal'. Los españoles de hoy no podemos menos que considerar con irreprimible nostalgia esa imagen de una España pluriracial, libre y alegre, en la que los signos "cuerpo" y "no cuerpo" se expresan en términos de complementaridad, imagen que, como sabemos, no volvemos a hallar después en la realidad ni en la literatura: no la patria ingrata y atroz, impuesta tras un fraude histórico de siglos, sino una patria habitable y acogedora, suelta de cuerpo y de mente, en la que algunos no dejamos de soñar ni siquiera cuando estamos despiertos--realidad frustrada por quienes consfiscaron de una vez para siempre, para sí y los de su especie, el país y la historia, el espacio y la lengua.

El libro de Octavio Paz nos ayuda a comprender mejor la metamorfosis posterior del signo "cuerpo" cuando establece el paralelo entre la diferente actitud respecto al mismo de Swift y de Quevedo. Mientras la oposición entre la noción de trabajo y la exuberancia sexual esclarece las relaciones existentes entre la moral puritana y el espíritu del capitalismo, la actitud del catolicismo español en lo que toca al cuerpo es mucho más ambigua puesto que, por motivos de casta, los cristianos viejos se acomodaban mal, igualmente, al imperativo racional del trabajo. El protestantismo abstrae el signo "cuerpo" y lo somete a las sublimaciones de la razón; el catolicismo español lo culpabiliza, tortura y retuerce, sin eliminarlo por ello del todo, y a su fresca y jugosa expresión en la obra del Arcipreste sucederá la expresión exasperada y convulsa de Quevedo y los poetas del barroco. Swift, dirá Paz, "es un escritor infinitamente más libre que el español pero su osadía es casi exclusivamente intelectual. Ante la virulencia sensual de Quevedo, especialmente en el nivel escatológico, Swift se habría ofendido', y en realidad "se enfrenta a prohibiciones no menos poderosas que las que imponían a Quevedo la neoescolástica, la monarquía absoluta y la Inquisición". Resumiendo: "a medida que la represión se retira de la razón aumentan las inhibiciones del lenguaje"', y la economía racional capitalista no se contenta con moralizar el oro y transmutarlo en signo sino que 
expulsa asimismo las palabras sucias y sublimiza y oculta la defecación inventando el Water-Closet automático. Por un lado: limpieza, racionalidad, sublimación; por otro: exasperación, violencia, escatología. Ello explica-como prueba Antonio Regalado en su estudio, todavía inédito, sobre el teatro de Calderón-que numerosas proposiciones morales sostenidas por los probabilistas españoles (en su mayor parte jesuitas) en la primera mitad del siglo XVII provocaran una reacción escandalizada a causa de su "laxitud" respecto a temas como fornicación, adulterio, aborto, etc., no sólo entre los panegiristas de la Reforma sino también entre Pascal y los jansenistas franceses, ya que la tensión dialéctica entre los signos cuerpo/no cuerpo tampoco operaba entre nuestros vecinos de la misma manera que en la Península.

Dicha realidad--escamoteada a menudo por nuestros ensayistas más estimables--nos conduce a la siguiente observación: el modelo inconsciente de censura intra-síquica, de censura incluida, como diría Freud, en el "mecanismo del alma" no puede actuar con la misma violencia sobre el cuerpo y la razón, y cuando actúa contra ésta lo hace a costa de descuidar hasta cierto punto a aquél y viceversa--como si careciera de poder para operar simultáneamente en ambos planos o, simplemente, supiera que, a la larga, el ser humano no lo toleraría. Una vez más, la posibilidad de un cuadro sinóptico de las relaciones de oposición, complementaridad y alternancia de los signos "cuerpo" y "no cuerpo" en Inglaterra, Francia y España aparece como una hipótesis fructífera que ningún espíritu reflexivo debería descartar a la ligera. En cualquier caso, las observaciones de Octavio Paz arrojan nueva luz sobre el arte y literatura españoles del Siglo de Oro y en lo futuro habrá que tomarlas muy en cuenta para analizar y comprender nuestro barroco. "Si el siglo XVII había olvidado que el cuerpo es un lenguaje--dice--, sus poetas supieron crear un lenguaje que, tal vez a causa de su misma complicación, nos da la sensación de un cuerpo vivo". El arte elusivo de Góngora, ese empeño típicamente suyo en evitar la mención de los objetos a fin de hacer salir al idioma de su transparencia ilusoria es, en verdad, el resultado de una lucha grandiosa, titánica para que el lenguaje cobre cuerpo--de una demencial porfía en imponernos, a brazo partido, la presencia opaca, densa, casi física de las escurridizas palabras.

No quisiera concluir estas notas sin referirme, aunque fuese brevemente, a la rebelión actual del cuerpo contra la filosofía moral del progreso y sus construcciones racionales omnímodas. Esta actitud, formulada por pensadores de la talla de un Bataille, se apoya en la distinción trazada por Marx entre trabajo alienado y no alienado para condenar, en nombre del cuerpo, la esclavitud del mundo industrial moderno y reivindicar la exuberancia sexual como único elemento humano irreductible a la cosificación. Dicho de otro modo: mientras el imperativo racional del trabajo tiende a convertir al hombre de hoy

${ }^{4}$ Entre las proposiciones de los probabilistas condenadas por Inocencio XI en 1679 figuran las siguientes: 1) comer y beber hasta hartarse, por solo el gusto, no es pecado, con tal que no dañe a la salud, porque lícitamente puede gozar de sus actos el apetito natural; 2) el acto conyugal, excitado por solo el deleite, carece del todo de culpa y defecto venial; 3 ) es lícito procurar el aborto antes de la animación de la criatura, para que la mujer preñada no sea muerta o infamada; 4) parece probable que todo feto, todo el tiempo que está en el vientre de la madre, carece de alma racional, y que entonces sólo comienza a tenerla cuando le paren, y consiguientemente se habrá de decir que en ningún aborto se comete homicidio; 5) la cópula con casada consintiendo el marido no es adulterio, y así basta decir en la confesión que ha fornicado; 6) lícito es buscar directamente la ocasión próxima de pecar por el bien espiritual o temporal nuestro o Jel prójims. Apud, Consultas morales y exposición de las proposiciones condenadas por Inocencio Undécimo, de Fray Murtín de Torrecilla, Madrid, 1684. 
en un objeto más en un mundo de objetos, la llamada animalidad preserva su conciencia de existir para y por sí mismo. Como escribe Bataille, "la vie humaine est excedée de servir de tête et de raison à l'univers. Dans la mesure où elle devient cette tête et cette raison, dans la mesure où elle devient nécéssaire à l'univers elle accepte un servage" --grito de asolada violencia que evoca irresistiblemente en el lector español el que vibra a lo largo y lo ancho de la Celestina. La tragicomedia de Rojas puede descifrarse en verdad como el clamor angustiado del signo "cuerpo" enfrentándose con la ideología dogmática que lo oprime, un clamor que no oimos ni antes ni después en las páginas de la literatura española en virtud quizá de la consabida, simultánea oposición de la casta cristiana vieja con respecto a la razón y el trabajo. Hoy, cuando España parece adoptarse por fin al esquema de un mundo racional y útil, sometido a las leyes económicas y la necesidad de un trabajo alienador y alienado, el cuerpo recobrará quizá la virulencia subversiva del grito. Pues la Celestina no es sólo una de las obras maestras de la literatura: es, igualmente, la expresión mordaz de nuestro anhelo corporal reprimido y, por tanto, una voz de protesta rabiosamente actual.

Independientemente de sus implicaciones en todo un haz de civilizaciones y culturas, los lectores españoles hallarán así en el libro de Octavio $\mathrm{Paz}$ una contribución indispensable al conocimiento de algunas de las conjunciones y disyunciones básicas de nuestra desdichada historia.

University of Pittsburgh

JUAN GOYTISOLO 
